\title{
A ética do cuidado no exercício da enfermagem: um olhar sobre os pacientes oncológicos \author{
The ethics of care in the practice of nursing: a look at the oncology patients
}

\author{
Suzana dos Santos Gomes* \\ Andrea Vaz dos Santos ** \\ Luciana Borges de Lima*** \\ Roberta Moura**** \\ Salomão Oliveira*****
}

\section{Resumo}

O objetivo deste artigo é analisar a ética do cuidado de enfermagem no tratamento de pacientes oncológicos. Optou-se pela pesquisa bibliográfica de abordagem qualitativa cuja metodologia foi dividida em etapas. Na primeira etapa, foi realizado um levantamento de artigos publicados, no período de 2000 a 2009, em periódicos do Scielo, utilizando os descritores: saúde/doença, enfermagem, ética do cuidado e oncologia. Esse levantamento culminou com a seleção de 28 artigos, 21 dos quais foram eleitos posteriormente para leitura aprofundada, assim como para utilização no estudo. Na segunda etapa, foram explorados dados do campo, com a transcrição e análise de depoimentos de profissionais da enfermagem sobre a concepção de cuidado bem como de dados sobre pacientes oncológicos, acompanhados no período de 2007 e 2008 . A pesquisa e suas exigências protocolares, sob o número CAAE - 0147.0.213.000-10, foi aprovada pelo Comitê de Ética da PUC Minas em 31 de agosto de 2010. O referencial teórico foi composto por autores que discutem o cuidado na perspectiva filosófica e teológica - Boff (2001, 2005 e 2006), Efken (2005) - e autores da área da saúde oncológica, entre eles, Carvalho et al. (2002), Popim \& Boemer (2005), Visentin, Labronici \& Lenardt (2007) e Araújo et al. (2009). Os resultados evidenciaram o cuidado na enfermagem como princípio ético essencial, assim como a necessidade de investimentos em políticas públicas de saúde no Brasil, que efetivem o trabalho de prevenção, educação e cura do câncer.

Palavras-Chave: Saúde/Doença; Enfermagem; Ética do cuidado; Oncologia.

\begin{abstract}
The objective of this article is to analyze the nursing care in the treatment of oncology patients. We have opted for bibliographical research of qualitative nature, a methodology divided into stages. In the first stage we gathered articles in a publication called Scielo from 2000 to 2009, which described: health/illness, nursing, ethics of care, and oncology. Through this process the selection of twenty-eight articles was accomplished, however only twenty-one articles were utilized in the production of this study. In the second stage field data were explored, we transcribed and analyzed the statements of nursing professionals on the conception of care and on oncology patients overseen by them in the period of 2007 to 2008. The research protocol and its requirements under the number CAAE - 0147.0.213.000-10, was approved by the Ethics Committee of PUC Minas on August 31, 2010. The theoretical support was provided by authors who discuss care in a philosophical and theological perspective: Boff (2001, 2005, and 2006), Efken (2005); and authors in the field of healthcare, among them Popim \& Boemer (2005), Silva et. al, (2005), Souza et al. (2005), Visentin, et al. (2007), and Araújo, et. al. (2008). The results demonstrated the care in nursing as an essential ethical principal, as much as the necessity of investment in public health policies in Brazil, for the effective promotion of cancer prevention, education and cure.

Key words: Health/Illness; Nursing; Ethics of Care; Oncology

Artigo recebido em 14 de abril de 2010 e aprovado em 22 de setembro de 2010.

* Doutora em Educação (UFMG), professora da PUC Minas. País de origem: Brasil. E-mail:

suzanasgomes@gmail.com

** Acadêmica de Enfermagem da PUC Minas. País de origem: Brasil.

*** Acadêmica de Enfermagem da PUC Minas. País de origem: Brasil.

${ }^{* * * *}$ Acadêmica de Enfermagem da PUC Minas. País de origem: Brasil.

***** Acadêmico de Enfermagem da PUC Minas. País de origem: Brasil.
\end{abstract}




\section{Introdução}

Este artigo tem por objetivo analisar a ética do cuidado no exercício da enfermagem, especificamente no tratamento de pacientes oncológicos. Trata-se de uma pesquisa constitutiva do projeto interdisciplinar do curso de graduação em Enfermagem da Pontifícia Universidade Católica de Minas Gerais. Tomou-se como referência o tema central Processo saúde/doença, proposta interdisciplinar do curso, investigando o recorte temático Ética do cuidado na enfermagem em pacientes oncológicos.

Considerou-se relevante a reflexão dessa temática, já que o ato de cuidar, intrínseco às ações de enfermagem, deve ser pautado em atitudes éticas de respeito ao paciente. Além disso, este estudo centra-se na possibilidade de contribuir como subsídio para a qualificação de profissionais da enfermagem e estudantes: juntamente com aspectos teóricos e práticos, poder-se-ão propor ações alternativas de qualificação do cuidado, o que envolve atenção às questões físicas, psicológicas, espirituais e sociais, possibilitando ao paciente a vivência digna do processo saúde/doença.

$\mathrm{O}$ cuidado de enfermagem tem seus fundamentos na filosofia, que responde à grande questão existencial do homem, tendo a ética, numa abordagem epistemológica, efetivamente comprometida com a emancipação humana. Com base nas contribuições de Boff (2001, 2002 e 2005), considera-se o cuidado de modo integral e holístico, envolvendo ações de prevenção e recuperação de doenças e ações de promoção e proteção da saúde, pois o cuidado humanizado faz a diferença na recuperação do paciente.

O cuidado holístico, na perspectiva de Waldow (2005 e 2008), implica acolhimento e confiança, estabelecimento de vínculos e atitudes de compaixão. Muitas vezes, o profissional da saúde não oferece esse tipo de apoio por falta de conhecimento de ações do cuidado, que envolve as dimensões física, psicológica, cultural, social, cognitiva e humanística. ${ }^{1}$ Para Carvalho et al. (2002), o cuidado inclui atribuições técnicas, mas, acima de tudo, pressupõe a capacidade de compreender o ser humano, perceber como ele está em seu mundo e como desenvolve sua identidade e constrói sua própria história de vida.

Quanto à metodologia, adotou-se a pesquisa bibliográfica de abordagem qualitativa. Trata-se de uma modalidade de pesquisa que busca entender um fenômeno por meio do

${ }^{1}$ Cf. SILVA \& ZAGO, 2001; COSTA, et, al. 2003; RECCO, et, al., 2005. 
trabalho com descrições, comparações e interpretações (GIL, 1999; CHIZZOTTI, 2006). De acordo com Gil (2002), a pesquisa qualitativa é desenvolvida no curso da aquisição dos conhecimentos e com a utilização cuidadosa dos métodos, técnicas e de outros procedimentos científicos.

A coleta de dados foi realizada no período de agosto a outubro de 2009. Na primeira etapa, foram eleitos periódicos nacionais e internacionais indexados na base de dados da Biblioteca Virtual em Saúde, que compreende a literatura relativa à base Scielo - Scientific Eletronic Library Online. Foram selecionados artigos cujo título, resumo e descritores apresentaram as seguintes palavras: saúdeldoença, ética do cuidado, enfermagem $e$ oncologia. Esse levantamento culminou com a seleção de 28 artigos, entre os quais foram eleitos 21 para leitura completa e utilização no estudo. Na segunda etapa, realizaram-se entrevistas semiestruturadas com profissionais da enfermagem que atuaram no acompanhamento de pacientes oncológicos no período de 2007 a 2008. As entrevistas transcritas e analisadas continham depoimentos desses profissionais sobre a concepção de cuidado e sobre sua experiência no atendimento a pacientes oncológicos. Considerou-se, nessa etapa, a orientação do Conselho Nacional de Ética na Pesquisa (Conep). ${ }^{2}$ Os sujeitos participantes tiveram acesso a todas as informações referentes ao projeto e assinaram o termo de consentimento livre e esclarecido, conforme determina a Resolução 196, de 10 de outubro de 1996, do Ministério da Saúde. Em sintonia com esses princípios, assegurou-se aos sujeitos o sigilo em relação às informações fornecidas na entrevista.

O processo de análise dos artigos iniciou-se com as orientações de Gil (2002) sobre a investigação qualitativa. Segundo esse autor, uma pesquisa bibliográfica compreende as seguintes etapas: leitura exploratória (rápida e com o objetivo de averiguar a magnitude de interesse da obra); leitura seletiva (com o objetivo de selecionar o material que servirá como referência na pesquisa); leitura analítica (organização clara e precisa, permitindo uma possível resposta ao objeto da pesquisa); leitura interpretativa (associação das leituras selecionadas com o objetivo estudado).

Esse levantamento culminou com a definição do referencial teórico da pesquisa, composto pelos seguintes autores: Boff (2001, 2005 e 2006); Efken (2005); Almeida \&

\footnotetext{
${ }^{2}$ Este projeto interdisciplinar foi registrado no Conselho Nacional de Ética na Pesquisa (Conep) conforme orientações do Ministério da Saúde para pesquisa envolvendo seres humanos. Folha FR - 348804 .
} 
Melo, (2001); Carvalho et al. (2002); Baumann \& Englert (2003); Popim \& Boemer (2005); Visentin, Labronici \& Lenardt, (2007) e Araújo et al. (2009).

Como o centro de interesse da pesquisa é o trabalho com pacientes oncológicos, faz-se necessário trazer algumas considerações sobre as especificidades da doença. Reconhecido como um problema de saúde pública, o câncer é uma doença que atinge o Brasil e o mundo. Atualmente é a segunda causa de morte no mundo ocidental, especialmente nos países em desenvolvimento, superada apenas pelas doenças cardiovasculares. A maioria dos pacientes toma conhecimento da doença quando esta já se encontra em estágio avançado. O impacto do diagnóstico é muito grande não só na vida do paciente, como também na de seus familiares.

Além de sintomas físicos como a dor, o câncer costuma causar sofrimento emocional, depressão e tornar a vida insuportável. Hoje, diferentes abordagens são utilizadas no acompanhamento dos pacientes oncológicos, e muitas ações têm contribuído para melhorar sua qualidade de vida. São ações que objetivam minimizar a dor e o sofrimento e que vão desde a utilização de técnicas simples até procedimentos mais avançados envolvendo o uso das novas tecnologias.

Pesquisas sobre o câncer realizadas no Brasil, como as de Barreto (2005) e Kroeff (2007), analisaram o aparecimento da doença levando em conta a causalidade, a ocorrência e as ações de controle.

A causalidade está associada à exposição da população aos fatores de risco e desenvolvimento do câncer. A doença, em parte significativa dos casos, associa-se a hábitos como consumo regular de bebidas alcoólicas, tabagismo, sedentarismo, má alimentação e obesidade. Seu aparecimento também pode estar ligado à frequente exposição ao sol. Além disso, o câncer foi identificado em trabalhadores que mantinham contato intenso com agentes cancerígenos presentes em produtos como o amianto e o alumínio.

A ocorrência diz respeito à incidência do câncer e aos índices de mortalidade no país. Publicações no campo da saúde $^{3}$ apresentam dados sobre essa incidência nas populações masculina e feminina. Sobre os homens, entre outros dados, pesquisas revelam

\footnotetext{
${ }^{3}$ Entre as publicações destacam-se a revista Informe-se em Promoção da Saúde; Revista Latino-Americana de Enfermagem e Acta Paulista de Enfermagem.
} 
que, entre 1979 e 2004, houve aumento de $95,48 \%$ na taxa de mortalidade por câncer de próstata. Também cresceu, nos homens, em 54,24\%, a taxa de mortalidade por câncer de cólon e reto. ${ }^{4}$ Nas mulheres, no mesmo período, estatísticas revelam que cresceu em 96,95\% a taxa de mortalidade por câncer de pulmão. Já a taxa de mortalidade por câncer de mama aumentou $38,62 \%$.

As ações de controle tratam de iniciativas para prevenção da doença, das formas de detecção precoce e rastreamento do câncer, das linhas de cuidado integral e tratamento, formação e educação permanente em oncologia. Um dos grandes problemas apontados pelo levantamento, de acordo com Barreto (2005) e Kroeff (2007), é que no Brasil, geralmente os tumores são diagnosticados em estágio avançado.

Popim \& Boemer (2005), em seus estudos sobre o câncer, destacam o progresso tecnológico da medicina na atualidade. De acordo com esses autores, os cuidados no final da vida passaram a ser realizados, sobretudo nos países desenvolvidos, em um ambiente impessoal, entre pessoas estranhas, sob o monitoramento de aparelhos eletrônicos. Por isso, eles chamam a atenção para a importância dos vínculos, do afeto e do acompanhamento humano na enfermagem.

Aliás, tendo em vista esse contexto, torna-se importante resgatar os princípios de compaixão e cuidado. Segundo Boff (2005), o cuidado tem muitas repercussões, sendo uma delas a compaixão. Trata-se da capacidade do ser humano de compartilhar o sofrimento ou alegrias com o outro, construindo a vida em sinergia. A compaixão envolve o desejo de estar com o outro, compadecer-se diante do sofrimento alheio. É uma solidariedade genuína, sentimento de base, que mobiliza os seres humanos na busca de melhores condições de vida. É na solidariedade que o diálogo se estabelece e que as crenças e saberes são respeitados. $\mathrm{O}$ autor ainda destaca, entre as concretizações do cuidado, o cuidado com nosso corpo na saúde e na doença. Para ele,

A doença remete à saúde. Toda cura deve reintegrar as dimensões da vida sã, no nível pessoal, social e no fundamental que diz respeito ao sentido supremo da existência e do universo. Por isso o primeiro passo consiste em reforçar a dimensão-saúde para que ela cure a dimensão-doença. (BOFF, 2001, p. 144).

\footnotetext{
${ }^{4}$ Cf. SANTOS et al. (2005); SCHUNEMANN (2009); ARAÚJO et al. (2009).
} 
Boff (2001) vê a saúde ante as várias situações que podem ser doentias ou sãs. Para ele,

Ser pessoa não é simplesmente ter saúde, mas é saber enfrentar saudavelmente a doença e a saúde. Ser saudável significa realizar um sentido de vida que engloba a saúde, a doença e a morte. Alguém pode estar mortalmente doente e ser saudável porque com esta situação de morte ele cresce, se humaniza e sabe dar sentido àquilo que padece. (BOFF, 2001, p. 144-145).

Diante desse quadro, destaca-se um importante papel do profissional da enfermagem: o de amenizar o sofrimento dos pacientes oncológicos. Popim \& Boemer (2005) sugerem algumas ações para melhorar o atendimento de pacientes com câncer, entre elas: manter uma cultura de cuidados paliativos, oferecer supervisão clínica adequada que inclua a ética do cuidado nas dimensões física, social, emocional e espiritual. ${ }^{5}$

Nesse sentido, o respeito aos pacientes portadores de câncer se constrói lentamente, e se busca através de uma relação de equilíbrio durante todo o processo de tratamento. $\mathrm{O}$ doente deve ser visto, no processo de trabalho, como um sujeito que não se limita apenas a um leito e a uma patologia. Consciente desse quadro, o profissional da enfermagem deve se colocar a serviço. Cuidar de pacientes com câncer exige, além do conhecimento, a compreensão, a valorização e, acima de tudo, o respeito ao outro, tendo em vista a obtenção de melhor qualidade de vida.

Este artigo, que aborda o cuidado com o paciente oncológico, está dividido em quatro partes. Na segunda parte, é apresentado o problema da saúde/doença no Brasil, destacando algumas iniciativas no campo da política de combate ao câncer, características e consequências. Na terceira parte, abordou-se a questão ética na sociedade contemporânea, explicitando o conceito de ética do cuidado na enfermagem. Na quarta parte, com base nos depoimentos de profissionais da enfermagem no tratamento de pacientes oncológicos, reafirmou-se a importância do cuidado no exercício da profissão enfermagem, em especial no tratamento de pacientes oncológicos. Nas considerações finais, foram apresentadas algumas conclusões obtidas neste estudo.

${ }^{5}$ Cf. ALMEIDA \& MELO, 2001; BOFF, 2001, 2005; BAUMANN \& ENGLERT, 2003. 


\section{0 problema da saúde/doença no Brasil}

Neste tópico, foram destacados alguns dados que revelam como o Brasil, ao longo da história, assumiu e criou políticas de saúde voltadas para o atendimento de pacientes com câncer. O objetivo é possibilitar uma compreensão dos efeitos de tais políticas sobre o processo de organização e reorganização dos serviços de saúde. Para tanto, adotou-se o critério de periodização, levando em conta o contexto socioeconômico e político próprio de cada época, a partir do início do século XX. As principais ações foram identificadas a partir da década de 20.

Historicamente, o câncer se constituiu num problema de saúde pública para todo o mundo, caracterizado como uma doença com localizações e aspectos clínico-patológicos múltiplos, que pode ser detectada em vários estágios de evolução histopatológica e clínica. O conhecimento do percurso histórico do tratamento do câncer no Brasil torna-se importante, pois o convívio com a doença vem permitindo o desenvolvimento de técnicas e métodos para o aprimoramento das ações de acompanhamento e sobrevida de pacientes oncológicos, sem as quais não seria possível o combate precoce da doença, ou o desenvolvimento de campanhas educativas de autoexame, como o do câncer de mama.

\subsection{Políticas de saúde para o tratamento do câncer no Brasil}

Neste tópico, são apresentados dados extraídos de Barreto (2005) e Kroeff (2007) que evidenciaram a falta de investimento e a ausência de políticas de saúde eficazes para a prevenção e tratamento do câncer. As ações no campo da saúde, historicamente vinculadas aos governos, de modo geral, se limitaram à criação de órgãos, e pouco impacto exerceram no combate ao câncer.

Na década de 20, surgiram as primeiras políticas públicas voltadas para o tratamento e controle do câncer e também medidas governamentais de apoio a iniciativas em prol da luta contra a doença no país. Nessa época, pouca ênfase foi dada à prevenção, pela escassez 
de conhecimento sobre a etiologia ${ }^{6}$ da doença - hoje, sabe-se que o câncer envolve fatores genéticos e componentes ambientais, alguns vírus, substâncias químicas variadas, responsáveis pelo aparecimento de tumores. Em outras palavras, os tumores são entendidos como o resultado de agressões ambientais em um indivíduo geneticamente suscetível.

Em 1920, foi criado o Departamento Nacional de Saúde Pública (DNSP), visando à ampliação do campo de ação assistencial. A partir de 1923, esse órgão passou a se chamar Departamento Nacional de Saúde (DNS).

A luta contra o câncer ganhou visibilidade em 1921 quando ocorreu o primeiro movimento de alcance social em São Paulo. Por deliberação do Dr. Arthur Bernardes, naquele ano foi implantado, em Belo Horizonte, o instituto Radium, pioneiro no país, destinado aos portadores de neoplasias. Em 1924, durante o Congresso Brasileiro de Higiene, foi apontado como preocupante o aumento dos casos de câncer nos principais centros urbanos do país. Na ocasião, a população cobrou do governo providências a respeito.

Durante o governo de Getúlio Vargas (1930 - 1945), a sociedade civil reivindicou ações de combate ao câncer, tendo sido criado, em 1937, o Centro de Cancerologia do Serviço de Assistência Hospitalar do Distrito Federal, no Rio de Janeiro, que veio a se constituir no atual Instituto Nacional de Câncer (Inca).

Já na década de 40, as iniciativas governamentais se voltaram para a reformulação e ampliação das diversas organizações de saúde. A necessidade de ampliar as ações na luta contra o câncer levou à criação, em 1941, do Serviço Nacional de Câncer (SNC). Esse órgão foi criado com o objetivo de orientar e controlar a doença no País.

A expansão da indústria químico-farmacêutica e dos equipamentos hospitalares aconteceu na década de 50. Sem dúvida, foi um marco para modificações profundas na política de saúde, principalmente na do câncer, dada a complexidade dessa doença, desde o diagnóstico até o tratamento. Nessa época, o governo se preocupou com a modernização dos cuidados médico-sanitários e com o uso de medicamentos e equipamentos hospitalares para a área da saúde.

\footnotetext{
${ }^{6}$ Etiologia pode ser entendida como os fatores genéticos e componentes ambientais, notadamente alguns vírus, certos agentes físicos e substâncias químicas variadas que têm papel decisivo no aparecimento de vários tumores humanos. (BARRETO, 2005).
} 
Nos anos 60, com o golpe militar, foram criadas várias redes privadas na área da saúde. Nesse contexto, o setor de saúde pública se viu abalado por irregularidades constantes, pela falta de investimentos e pelo gerenciamento inadequado das verbas disponíveis.

O Programa de Controle ao Câncer (PCC) foi fruto do convênio entre o Ministério da Previdência e Assistência Social (MPAS) e o Ministério da Saúde (MS), em 1975. Esse convênio possibilitou a universalização de procedimentos relacionados à doença, como a criação, nos níveis local, estadual e federal, de comissões de oncologia com o objetivo de integrar as ações do extinto Departamento Nacional do Câncer (DNC).

Apesar do milagre econômico da década de 70, os benefícios almejados para a área da saúde não sofreram alteração. Pelo contrário, a escassez de recursos destinados ao setor resultou no aumento do número de pessoas desassistidas. Nesse período, não houve nenhum investimento no campo da oncologia.

O aumento da pobreza e da miséria, as altas taxas de desemprego, a desvalorização do salário mínimo, com consequentes medidas recessivas, marcaram a década de 80, conhecida como a "a década perdida". Com o agravamento da crise, o governo promoveu a integração entre as assistências preventiva e curativa.

É possível constatar que, nos últimos anos, o governo investiu pouco em políticas públicas de saúde, situação que foi agravada com o fim da Contribuição Provisória sobre a Movimentação Financeira (CPMF). No que se refere à área oncológica, há uma tímida iniciativa relacionada ao câncer de mama que garantiu às mulheres, a partir dos 39 anos de idade, acesso à mamografia pela rede do Sistema Único de Saúde (SUS). ${ }^{7}$

É importante destacar que existem vários projetos de $1 \mathrm{ei}^{8}$ que contemplam principalmente a prevenção do câncer de mama, de próstata, do colo do útero e do pulmão, mas que ainda não foram votados. Observa-se, nesse breve recorte histórico do Brasil, que as políticas de saúde não caminharam a contento, deixando a desejar no aspecto mais importante: a qualidade de vida da população brasileira, especialmente a classe menos favorecida social e economicamente.

\footnotetext{
7 Cf. BARRETO, 2005 e KROEFF, 2007.

8 Dentre os projetos de lei, citamos PL 4820/05, PL 4089/98 e PL 3018/04.
} 
Diante desse quadro complexo no campo da saúde, esta pesquisa reforça, especialmente, a necessidade de se aumentarem os investimentos em atendimento e em exames para o diagnóstico precoce do câncer. O grande desafio para o controle do câncer no Brasil está no campo da mobilização social. Defende-se a articulação de políticas de saúde com políticas de educação, rompendo preconceitos e quebrando o paradigma de que o câncer é sinônimo de morte, pois, quando diagnosticado na fase inicial, é grande a possibilidade de cura.

\section{A redescoberta da reflexão ética na sociedade contemporânea}

Nesta parte, pretende-se relacionar a reflexão ética com os desafios no campo da saúde, em especial no acompanhamento de pacientes oncológicos. Inicialmente foi levantada a seguinte questão: qual é a relação entre saúde/doença e a ética do cuidado?

A reflexão sobre a ética e moral na sociedade contemporânea, questão em pauta e discutida atualmente em todos os níveis do convívio social, tem mobilizado o cidadão para repensar o modo de viver, de agir, de tratar o outro, ou seja, de se colocar diante da vida. Desse modo, ela ocupa hoje espaço nos meios de comunicação social, na organização empresarial, nos debates políticos e nos cursos universitários. Em congressos nacionais e internacionais, discutem-se questões ligadas à ecologia, à fome, à saúde, à educação, evidenciando-se a atualidade do tema da ética em todos os âmbitos da vida humana (EFKEN, 2005).

De acordo com Efken (2005), diversas situações colocam em cheque a validade e eficácia dos modelos éticos e morais herdados do passado, como a eclosão de conflitos bélicos, o agravamento dos conflitos sociais, a insatisfação com a má distribuição de renda, a crescente desigualdade entre os países desenvolvidos e os países em desenvolvimento, além do abismo entre os ricos e pobres. Para esse autor, a dura realidade nos impõe uma reorientação radical relacionada ao nosso modo de viver, de agir e de pensar.

A crise generalizada exige uma resposta de todos e se apoia numa racionalidade aberta ao diálogo, à comunicação, ao respeito ao diferente e 
orientada ao entendimento entre todos os envolvidos na construção e reconstrução das realidades humanas. (EFKEN, 2005, p.105).

O conhecimento a respeito da ética é uma necessidade para a convivência social, política, cultural e econômica, e não apenas um passatempo de alguns teóricos e acadêmicos. Portanto, "a problemática ética deve tornar-se preocupação permanente de todos os que participam efetivamente do planejamento e da construção da convivência humana pacífica em sociedade" (EFKEN, 2005, p.111).

A vida é um permanente processo de discernimento, de avaliação, de busca e de escolha. Somos eternamente responsáveis por ela e não há como fugir dessa responsabilidade (EFKEN, 2005). À luz dessa perspectiva, defende-se a importância do cuidado na sociedade contemporânea, pois "quem não sabe cuidar de si mesmo, dificilmente saberá cuidar dos outros, quem não sabe estar consigo mesmo, terá problemas em estar com os outros" (EFKEN, 2005, p.116).

\subsection{O porquê da ética na saúde}

A crise presenciada na sociedade contemporânea tem a marca do descuido (BOFF, 2005). A sociedade contemporânea está cada vez mais criando falta de comunicação, solidão e desrespeito entre as pessoas. Carvalho et al. (2002) lembram com pertinência que o cuidar, objeto de trabalho da enfermagem durante toda a sua história, passou por várias transformações e chega ao século XXI centrado na fragmentação do indivíduo.

É sobretudo a partir da última década do século passado que o alívio do sofrimento começa a ser entendido como um componente importante dos cuidados profissionais de saúde. O crescente aumento das doenças crônicas, relacionado, por um lado, com os avanços terapêuticos e, por outro, com as alterações demográficas, tornou o sofrimento um problema de domínio público, suscitando a discussão sobre o seu reconhecimento e alívio. Embora não se possa viver a angústia do outro, pode-se entender seus sentimentos e, através destes, perceber situações vivenciadas e vislumbrar maneiras concretas de cuidar. No caso específico de pacientes com câncer, isso implica compreender que o sofrimento 
perante a doença não se limita a um determinado tempo e espaço, mas assume características existenciais bem claras e distintas em diferentes contextos sociais. ${ }^{9}$

Desde a sua origem, a enfermagem tem compreendido e sustentado o cuidado como valor e prática. Assim, o resgate da ética do cuidado é fundamental para o respeito e a valorização do outro em sua complexidade. Estreitamente ligada às terminologias da área da saúde, cuidado, em latim, significa cura. Trata-se de uma atitude fundamental, um modo de ser, no qual a pessoa sai de si e se volta para o outro, visando proteger, promover e preservar a vida, independentemente de circunstâncias internas ou externas.

Zoboli (2004) e Waldow (2005 e 2008) consideram o cuidado como central na enfermagem. Desse modo, para as autoras, cuidar em enfermagem envolve promoção da vida, assim como ajuda ao outro para que ele cresça no autoconhecimento, no controle e na autocura. Essa concepção de cuidado tem suas bases na compaixão, na sensibilidade e na capacidade de estar com o outro.

Boff (2001) apresenta o pathos como sentimento. Pathos é também a capacidade do ser humano de sentir empatia e compaixão pelo outro. Souza et al. (2005), por sua vez, descrevem o cuidado de enfermagem como pertencente a duas esferas distintas: uma objetiva e a outra subjetiva. A esfera objetiva está relacionada aos procedimentos técnicos no campo da saúde: é a habilidade técnica para desenvolver procedimento no paciente. Já a esfera subjetiva tem como fundamento a sensibilidade, o respeito, o amor, a observação e o toque, ou seja, trata-se de uma visão holística, que vê o outro como pessoa.

Portanto, a ética do cuidado em Boff (2004) e em Souza (2005) integram atendimento e respeito. $\mathrm{O}$ cuidado é considerado a essência do ser humano. $\mathrm{O}$ cuidado salva vidas.

\section{2 Ética do cuidado na enfermagem e na oncologia}

Para entender a ética do cuidado na enfermagem, foram exploradas as contribuições de Almeida \& Melo (2001), Carvalho et al. (2002), Silva (2005), Popim \& Boemer (2005) e Boff (2005). Para todos eles, o cuidado cria possibilidades, favorece condições de

${ }^{9}$ Cf. ALMEIDA \& MELO, 2001; POPIM \& BOEMER, 2005. 
pertencimento, além de significar o "modo de ser do homem no mundo" (BOFF, 2001, p. 96).

Boff (2005) apresenta uma concepção holística do cuidado. Para o autor, uma pessoa é ética quando se orienta por princípios e convicções. Etimologicamente, a palavra ética deriva de ethos. Boff (2005) apresenta o ethos como sendo a ética. O ethos inclui o caráter, o modo de ser essencial. Dessa forma, para o autor, "somente esse ethos que ama pode responder aos desafios atuais que são de vida e de morte" (BOFF, 2005, p.47).

Para Boff (2005), o cuidado constitui a categoria matricial do novo paradigma da civilização que emerge na contemporaneidade. Com base nas suas contribuições, pode-se afirmar que o ethos que ama se completa no ethos que cuida. Coerentemente, cuidar em enfermagem, na concepção de Boff (2005,) implica envidar esforços para proteger, promover e preservar a vida, consequentemente, ajudar pessoas a encontrarem significado na doença, no sofrimento, como também, na vida, em geral.

Para Silva et al. (2005), no campo da enfermagem, o cuidado se revela na sua dimensionalidade moral, ética, ambiental, cultural, política e econômica. No dizer da autora, a busca de produção e conhecimento sobre o cuidado em enfermagem compreende entender a ação de cuidar como arte e ciência (SILVA et al. 2005).

Como se vê, o cuidado envolve uma dimensão ampla e inconfundível:

O cuidado de enfermagem é inserido no âmbito político e ético, entendemos que uma formação humanística contrapõe-se à mera operacionalidade e do sentido existencial ao cuidar. Assim, pensar em modos ou modelos de cuidar em enfermagem requer compreensão do sentido e do significado desse cuidado, sua dimensão política e sua implicação sobre a vida dos cidadãos. (SOUZA et al. 2005, p.4 ).

Silva (2005) vê também o cuidar em enfermagem como "luz e energia". Luz porque o cuidado é considerado função primordial para a sobrevivência de todo ser vivo. Energia, porque é na relação do cuidado que a enfermagem se fortalece. É possível dizer então que cuidar é e sempre será indispensável, não apenas à vida do indivíduo, mas à perenidade de todo o grupo social. Portanto, "o cuidado é parte integrante do processo de sobrevivência da vida humana" (SOUZA et al. 2005, p.3). 
Cuidar do outro de forma ética exige preparo técnico e procedimental, e, além disso, compreensão, empatia, aceitação e adoção de uma postura que permita reconhecer o outro como ser de totalidade única. Assim, “[...] inúmeros são os aspectos éticos que envolvem o cuidar, mas essencialmente, todo procedimento de enfermagem deve ser conduzido de acordo com a justiça e com os princípios básicos como respeito pela pessoa" (BARROS, 2003, p.53).

No que diz respeito aos princípios éticos, o respeito à pessoa é considerado fundamental. O paciente deverá ser consultado ao longo do seu tratamento. E sua autonomia e opinião devem ser consideradas na tomada de decisão. Antes do exame ou de qualquer procedimento, o paciente deve receber informações adequadas sobre o seu quadro. Para facilitar, recomenda-se o uso de linguagem e terminologia acessíveis à escolaridade e ao nível cultural do paciente.

Barros (2003) lembra que o enfermeiro deve estar disponível para atender o paciente no que diz respeito aos exames e procedimentos de enfermagem a serem realizados. É seu dever garantir proteção para o paciente que tenha autonomia reduzida. Além disso, o profissional da enfermagem, como técnico da área, deverá dar o consentimento para a realização dos procedimentos previstos, garantindo uma relação humana no atendimento de saúde.

Para ele, o profissional da enfermagem deve considerar o paciente como um ser livre, merecedor de respeito e garantir que a assistência de enfermagem seja praticada em níveis éticos apropriados: cuidar de uma pessoa implica acolhimento, respeito e segurança, em outras palavras significa "entrar em sintonia com ele, auscultar seu ritmo e afinar-se com ele" (BARROS, 2003, p.54). A prática do cuidado no exercício da enfermagem vai garantir o bem-estar do paciente ao longo do seu tratamento e vai ser decisiva na sua recuperação.

De acordo com Souza et al. (2005), o cuidado na enfermagem promove e restaura o bem-estar físico, psíquico e social e amplia as possibilidades de vida. Portanto, envolve o componente humanístico de proteção e defesa da vida. Baseia-se em ações que se estendem para a construção da cidadania, porque potencializa a expressão do cuidado em sua existência social. Agrega uma série de ações profissionais próprias da enfermagem, e se concretiza em práticas interdisciplinares. 
No que diz respeito à ética do cuidado, destaca-se especialmente, neste trabalho, o cuidado com pacientes oncológicos, os quais apresentam necessidades bem peculiares relacionadas ao seu quadro clínico. Além de atender o paciente, o profissional da enfermagem deve estar preparado para dar apoio à família do paciente, ao longo do tratamento. Para Boff (2005), Popim \& Boemer (2005) e Schünemann (2009), esse apoio e acompanhamento devem abranger diferentes dimensões: a física, a emocional, a cultural, a ético-religiosa e a técnica.

Torna-se importante ainda salientar que cuidar em oncologia implica lidar com o humano em situação de fragilidade, envolve uma relação de afetividade revestida de grande complexidade, requerendo do profissional uma competência que supera a esfera técnicocientífica. Por esses motivos, Popim \& Boemer (2005) recomendam o uso de estratégias que minimizem o desgaste a que é submetido esse profissional no acompanhamento de pacientes oncológicos.

\section{A ética do cuidado em oncologia na ótica da enfermagem}

Estudos sobre a ética do cuidado e sobre o cuidar em oncologia atestam que a enfermagem, desde a sua origem, tem no cuidado seu princípio de atuação. ${ }^{10}$ Segundo Recco et al. (2005), a enfermagem se preocupa com o cuidado da pessoa em diferentes situações relacionadas à saúde. Numa perspectiva interdisciplinar, enquanto a medicina está envolvida com a cura do paciente, a enfermagem está voltada para o cuidado do paciente em todas as dimensões. Esse cuidado inclui papéis significativos na educação para saúde e na prevenção de doenças. No caso específico do paciente com câncer, cuidar implica não só conhecer a patologia, mas também saber lidar com o paciente através da escuta qualificada de suas queixas clínicas, na execução de ações eficazes, de caráter ativo, preventivo e de suporte.

\footnotetext{
${ }^{10}$ Cf. FERREIRA, 1996; POPIM \& BOEMER, 2005; VICENTIM, LABRONICI, LENARDT, 2007; SCHÜNEMANN, 2009.
} 


\subsection{Aspectos éticos envolvidos no cuidar de paciente oncológico}

Com base nesses princípios, a pesquisa de campo teve início com a entrevista a profissionais de enfermagem ${ }^{11}$ que atuavam em unidades oncológicas. O objetivo do grupo de pesquisa foi identificar a concepção de cuidado para quem lida com pacientes oncológicos. Assim, membros do grupo de estudo Saúde/Doença utilizaram o instrumento entrevista com profissionais da enfermagem para saber o que significava para eles cuidar de paciente oncológico e como eles definiriam o cuidado.

Os depoimentos revelaram a concepção de cuidado que tem norteado as ações desses profissionais:

[...] são pacientes fragilizados, com uma história de vida por trás da doença. A paciência vem em primeiro lugar, o carinho e a atenção são essenciais. Muitas vezes já estão em fase terminal e necessitam de muita atenção. $\mathrm{O}$ apoio da enfermagem nesse momento é muito importante. [...] $\mathrm{O}$ ato de ouvir seus medos, esclarecer suas dúvidas é muito importante, pois o paciente oncológico passa por todo um tratamento invasivo, a quimioterapia e a radioterapia na maioria das vezes, tratamentos complicados, durante os quais ocorrem mudanças físicas como a queda do cabelo, prostração, mal-estar entre outros. Então o cuidado de enfermagem se baseia na paciência, carinho e ética profissional. (Paula Mendes ${ }^{12}, 23$ anos, Enfermeira)

Consciente dos desafios, especificamente no tratamento de pacientes oncológicos, cada profissional da enfermagem vai encontrando formas de se preparar para melhor cuidar. É o que revelam alguns depoimentos:

Cuidar de pacientes oncológicos é difícil, porém é supergratificante. Eu aprendia muito a valorizar pequenas coisas e mínimas atitudes que eu deixava passar despercebidas anteriormente a esse cuidado. Para cuidar me baseio no amor e na ética, respeitando sempre e acima de tudo o direito de decidir na sua individualidade. Do contrário, jamais chegarei a lugar algum [...]. (Vera Lima, 37 anos, Enfermeira)

\footnotetext{
${ }^{11}$ Adotaram-se nomes fictícios para todos os profissionais da Enfermagem e pacientes citados nesse artigo. 12 Nome fictício.
} 
Os princípios da autonomia e da veracidade preconizam que é direito do paciente conhecer o seu estado de saúde. Informações claras e compreensíveis, originadas das relações entre profissionais de saúde e pacientes, constituem base necessária para que estes possam decidir entre consentir ou recusar a terapêutica proposta, ou ainda, estabelecer ou ajustar suas expectativas futuras. O modo como a informação será transmitida assume caráter fundamental, sendo necessário que o profissional esteja atento para ouvir seus pacientes e que seja sensível aos seus questionamentos, esclarecendo dúvidas sobre seu estado de saúde, assegurando que cada indivíduo obtenha respostas completas, honestas e satisfatórias. ${ }^{13}$.

Os depoimentos obtidos revelam que o profissional da enfermagem adquire, no acompanhamento de pacientes oncológicos, maturidade profissional para cuidar, pautando suas ações e palavras em princípios éticos. ${ }^{14}$

\section{2 Ética do cuidado: ouvindo pacientes oncológicos}

Nesta parte, apresentam-se alguns casos de pacientes oncológicos acompanhados ao longo do seu período de internação e tratamento. Membros do grupo de estudo, atuando como técnicos de enfermagem, tiveram a oportunidade de acompanhar, por alguns meses, esses pacientes no período de 2007 a 2008. Os relatos apresentados a seguir foram extraídos de diários de campo desses profissionais.

O primeiro narra a história de Emília:

Emília Martins Silva, 60 anos, residente em Pirapora, MG. A paciente deu entrada no Hospital Odilon Behrens em Belo Horizonte, com quadro de dor e perda de sensibilidade dos membros inferiores. Após exame de ressonância magnética, foi diagnosticada massa compressiva. A paciente foi operada para descompressão dessa massa. Depois de alguns dias de internação foi realizada biópsia do tecido, através da qual foi diagnosticado um quadro de mieloma múltiplo, sendo então iniciado o tratamento paliativo para eliminação da dor. A paciente necessitou de auxílio da enfermagem para sua higiene corporal, pois não deambulava. Ao longo de seu tratamento, Emília contou com a ajuda de seus familiares, principalmente do cuidado manifestado pelo filho. Esse apoio

\footnotetext{
${ }^{13}$ Cf. POPIM \& BOEMER, 2005; VICENTIM, LABRONICI, LENARDT, 2007; SCHÜNEMANN, 2009.

${ }^{14}$ Cf. ALMEIDA \& MELO, 2001; VISENTIN et, al.(2007) e ARAUJO et, al. (2009).
} 
contribuiu muito para seu processo de recuperação. A paciente superou a crise após dois meses de tratamento. Iniciou a quimioterapia no Hospital Luxemburgo. Após várias sessões, obteve recuperação. Emília iniciou um programa de fisioterapia na PUC Minas Coração Eucarístico com duração média de quatro meses. Com o término da fisioterapia, a paciente retornou à sua cidade de origem. Após um ano da sua recuperação, Emília começou a ter queda da sua própria altura, perdendo o equilíbrio das pernas. Por esse motivo, retomou a Belo Horizonte e foi internada no Hospital Luxemburgo. Com os novos exames, verificou-se que havia reincidido o tumor e a paciente voltou a apresentar um quadro depressivo. Após um mês de tratamento, Emília teve uma parada cardiorrespiratória (PCR), foi reanimada e levada para o CTI. Infelizmente não houve resposta positiva e a paciente veio a falecer.

O segundo apresenta a história de Ana Martins:

Ana Martins, 23 anos, residente em Sabará, foi internada na Unidade de Oncologia de um hospital para tratamento de câncer de laringe. Ana era uma paciente muito triste, deprimida e de poucas palavras. Além disso, a sua condição clínica a impedia de verbalizar normalmente, possibilitando somente a emissão de alguns sons, pois ela estava afônica e nessa época, a tristeza a dominava. A paciente se alimentava por uma sonda naso entérica (SNE) e respirava ar ambiente via traqueostomia (TQT). Sensibilizada com o estado de Ana, uma técnica de enfermagem tentou se aproximar e oferecer conforto. Após várias tentativas, Ana se abriu e passou a aceitar os cuidados e a atenção oferecidos pela técnica de enfermagem. A mudança de Ana foi surpreendente. A paciente passou a sorrir, seus olhos e face ganharam nova cor e, como não podia falar, passou a expressar seus sentimentos através da escrita de mensagens, cartas etc. Aos poucos, sua condição clínica foi estabilizada. Ana aprendeu a ingerir líquidos por via oral e estava prestes a remover a traqueostomia. Essa melhora significativa, sem dúvida, foi influenciada pelo cuidado que a paciente recebeu e que passou a valorizar e canalizar, passando a ser uma referência para a busca e construção do sentido da vida, mesmo em situação de sofrimento e enfrentamento do câncer.

\section{O terceiro é o relato da história de Célia Oliveira:}

Célia Oliveira, 27 anos, residente em Governador Valadares, permaneceu internada na Unidade de Oncologia para tratar do câncer na laringe. Ela era triste e deprimida. Além disso, a sua condição clínica não permitia verbalização normal. A paciente emitia apenas alguns sons. Célia se alimentava por uma SNE e respirava através da via TQT. Sensibilizada com a situação de Célia, uma enfermeira tentou se aproximar. Mas foi rejeitada. Após várias tentativas, Célia se abriu e mudou completamente a sua postura. Os olhos de Célia passaram a brilhar e todos notaram a

mudança no seu comportamento. A paciente passou a escrever textos, mensagens e nessa 
atividade permanecia por longo tempo. Quem conheceu Célia antes ficou admirado com a mudança. Aos poucos, a paciente obteve estabilização do quadro e voltou a ingerir líquidos pela via oral. A melhora significativa na vida de Célia se deu graças ao cuidado que recebeu e começou a compartilhar.

O quarto conta a história de Sérgio Pereira:

Sérgio Pereira, 29 anos, residente em Ipatinga, foi internado na Unidade de Oncologia para tratamento de leucemia mieloide aguda (LMA). Confiante e atento a tudo o que ocorria, Sérgio era comunicativo e manifestava gratidão pelo atendimento recebido e pela presença amiga dos seus familiares. Nas conversas diárias, Sérgio elogiava o atendimento da equipe de enfermagem e reconhecia que estava vivo, com coragem e força para lutar contra o câncer graças ao cuidado e atendimento que recebia.

Esses e outros casos do campo oncológico revelam a importância do cuidado, da assistência qualificada como fundamentais para alcançar resultados positivos no tratamento do câncer e, assim, obter benefícios para aqueles que buscam os serviços de atenção à saúde. Portanto, a preocupação com a qualidade de vida dos pacientes deve estar constantemente presente no exercício profissional da enfermagem.

Cabe ainda acrescentar que a responsabilidade da enfermagem no tratamento de pacientes oncológicos é complexa e marcada pela diversidade. Nesse contexto, o profissional da enfermagem deve estar pronto para dar apoio ao paciente e sua família, ao longo do tratamento, o que implica saber lidar com as crises físicas, emocionais, sociais, culturais e espirituais provocadas pela doença. Essa ação requer planejamento, a fim de oferecer apoio aos pacientes submetidos ao tratamento, tendo em vista os modelos assistenciais e o processo de enfermagem como base desse tratamento. Existe um desafio inerente aos cuidados de paciente com câncer, pois o portador dessa doença tem, em sua patologia, dor, sofrimento e morte, sendo estes alguns dos motivos que influenciam mudanças em seu comportamento (RECCO et al., 2005).

Diante desse quadro, torna-se importante salientar que o cuidado com a saúde do outro envolve muito mais do que a dimensão técnica e procedimental. E de acordo com Recco et al. (2005), é importante conhecer o paciente e seus familiares, vendo-os como pessoas singulares que vivenciam uma difícil etapa de suas vidas - a luta contra o câncer. 
Os pacientes oncológicos, ao longo do tratamento, vão deparar com vários medos, e o medo da morte estará sempre presente. Na fase terminal, de acordo com Barreto (2005), os pacientes podem experimentar cinco etapas que caracterizam esse processo de morte: negação, cólera, barganha, depressão e aceitação.

$\mathrm{Na}$ fase de negação, o paciente busca mobilizar suas defesas, evitando falar na morte. E, geralmente esta fase compreende uma defesa temporária, que é substituída, com o passar do tempo, por uma aceitação parcial. Nesse período, o paciente pode passar por um estado de choque. Na fase da cólera, vemos a negação ser substituída por ira. A raiva pode ser direcionada à equipe de enfermagem.

$\mathrm{Na}$ fase denominada barganha, vemos o paciente tentando adiar o inevitável - a morte. Na tentativa de prolongar a vida, ele tenta barganhar com Deus e promete que se tudo correr bem, irá mudar de vida. Já no estágio da depressão, o paciente se prepara para aceitar a perda de tudo e de todos que ele ama. Trata-se de uma fase complexa, que exige muita atenção e acompanhamento.

Finalmente, na fase de aceitação, o paciente se mostra conformado com seu quadro. Ele se curva e aceita a sua realidade. Nessa fase, a família pode enfrentar uma crise de depressão e necessitar de apoio, enquanto o paciente pode manifestar-se mais tranquilo, como também pode revelar desejo de encerrar a etapa de sofrimento.

Cabe salientar que as fases descritas acima podem apresentar diferenças, não se apresentando necessariamente nessa sequência. O predomínio de uma ou de outra vai depender de diferentes fatores físicos, emocionais, culturais e religiosos. Destacamos nessas fases o papel do profissional da enfermagem. Caberá a ele oferecer um acompanhamento que permita ao paciente viver o mais intensamente possível, aliviando o desconforto e o incômodo próprios de cada fase, estabelecendo harmonia com as necessidades especiais de quem está diante da morte e deve receber total assistência para morrer com dignidade.

Os princípios básicos que fundamentam as reflexões éticas no processo de conduta terapêutica foram propostos por Silva (1998). Para a autora, esses princípios se interrelacionam de forma dinâmica, sendo que o contexto e a situação do paciente oncológico vão definir a melhor opção terapêutica em uma dada situação. Os princípios descritos por Silva (1998) são: autonomia, beneficência, não-maleficiência e justiça. 
Autonomia ou autodeterminação é a liberdade de uma pessoa agir conforme seus valores, prioridades, desejos e crenças pessoais. O princípio da autonomia está implicado também em questões complexas, como o desejo do paciente com doença avançada de que não sejam realizadas condutas terapêuticas que adiem o processo de morrer.

Já o princípio da beneficência envolve a atuação em favor do bem-estar ou beneficio de alguém, a fim de aliviar ou evitar o mal ou qualquer tipo de dano. Inclui a utilização de todos os procedimentos que possam aliviar o sofrimento dos pacientes e de seus familiares.

A não-maleficiência é a proteção garantida pelos profissionais da enfermagem atentos a tudo o que acontece ao paciente, lembrando que pessoas com câncer são frágeis, vulneráveis e assustadas. Elas necessitam de um compromisso forte de que não sofrerão nenhum dano através dos cuidados que lhes serão proporcionados.

Por fim, a justiça implica o direito de as pessoas terem oportunidade de acesso aos cuidados de saúde de forma equitativa. É preconizado também que pacientes sem possibilidade de cura tenham acesso garantido aos cuidados de saúde, não devendo ser encarados como prioridade menor.

\section{Considerações finais}

As demandas sociais têm chamado atenção para uma crescente desumanização do ser humano. Os crescentes avanços tecnológicos tendem a exigir da enfermagem capacidades para enfrentamento de questões éticas e morais no campo da saúde. Nesse sentido, pesquisas sobre o cuidado aumentam o conhecimento dos profissionais da saúde e servem de subsídios para nortear e orientar sua prática.

Este estudo também reafirmou o cuidar como uma ação inerente à profissão da Enfermagem, considerando em especial o significado do cuidar no campo oncológico. Coerente com essa perspectiva, possibilitou o aprofundamento na ética do cuidado, tomando como referência as contribuições de autores do campo filosófico, teológico e da área da saúde.

Para atuar no campo oncológico, o profissional da saúde deverá adquirir conhecimentos técnico-científicos próprios da área da saúde, e, além disso, desenvolver 
capacidades para cuidar do ser humano na sua integralidade, exercendo uma ação singular nas dimensões física, psíquica, social e espiritual.

Com base na análise dos dados obtidos neste trabalho, são apresentadas algumas considerações.

Uma primeira consideração diz respeito ao projeto interdisciplinar do curso de Enfermagem. Trata-se de uma proposta de trabalho que interfere positivamente na formação dos graduandos, preparando-os para atuar com competência no campo profissional, além de incentivar a prática multiprofissional no campo da saúde.

Uma segunda consideração está ligada às políticas públicas de saúde. Este estudo evidenciou a ausência de uma política eficaz no combate ao câncer. Identificamos, ao longo das últimas décadas, ações dos governos que não conseguiram conter o avanço dessa doença crônica, bem como a falta de investimento nas ações de educação e prevenção. As ações do governo caminharam em paralelo, deixando a desejar no aspecto mais importante: a qualidade de vida da população brasileira, especialmente, da classe menos favorecida social e economicamente.

Uma terceira consideração presente neste estudo está ligada ao modo de ser cuidado proposto por Boff (2002). Ressalta-se a importância de o profissional da enfermagem desenvolver uma atitude de zelo e compaixão, em especial no tratamento de pacientes oncológicos. Desse modo, o respeito, o saber ouvir, o estar com o outro são posturas éticas que favorecem a relação de confiança entre o paciente e o profissional da enfermagem. Além disso, considera-se importante dar atenção à espiritualidade do doente, o que implica aprender a ouvir, estar presente, numa busca contínua pelo sentido da vida. Intervenções de caráter espiritual podem proporcionar ajuda, permitindo enfrentamento de medos, amadurecimento, crescimento da esperança e apoio na procura de significados.

Finalmente, esta reflexão ética sugere novos estudos que envolvam a atenção de enfermagem na oncologia e em outras áreas da saúde, tendo em vista o enfrentamento dos dilemas éticos e o cuidado humanizado em saúde. 


\section{Referências}

ALMEIDA, J.M; MELO, J. S. Ética, espiritualidade e oncologia. In: DIAS, M.R.; DURÁ, E. (coords.). Territórios da Psicologia Oncológica. Lisboa, Climepsi, 2001, p. 129-143.

ARAÚJO, L. Z. S.; ARAÚJO, C. Z. S.; SOUTO, A. K. B. A.; OLIVEIRA, M. S. Cuidador principal de paciente oncológico fora de possibilidade de cura, repercussões deste encargo. Revista Brasileira de Enfermagem Jan/Fev 2009.

Disponível em: <http://www.scielo.br/pdf/reben/v62n1/05.pdf>. Acesso em: 21 set. 2009.

BARRETO, E. M. T. Acontecimentos que fizeram a história da oncologia no Brasil: Instituto Nacional do Câncer (INCA). Revista Brasileira de cancerologia. v.3, n.51, 2005, p.267-275.

BAUMANN, S.L.; ENGLERT, R. A comparison of three views of spirituality. Nursing Science Quarterly, (1), 2003, p. 52-59.

BEOZZO, J. O. Saúde: cuidar da vida e da integridade da criação. São Paulo: Paulus, 2002, cap.3, p.90-108.

BOFF, L. Saber cuidar: ética do humano, compaixão pela terra. 7. ed. Rio de Janeiro: Vozes, 2001.

BOFF, L. Ética e moral: a busca dos fundamentos. 2. ed. Petrópolis: Vozes, 2004.

BOFF, L. O cuidado essencial: principio de um novo ethos. Inclusão Social, Brasília, v.1, n.1,p.28-35, out./mar.2005.

BRASIL. Ministério da Saúde. Instituto Nacional de Câncer. Ações de enfermagem para o controle do câncer: uma proposta de integração Ensino - Serviço. 2 ed. Rio de Janeiro 2002.

CARVALHO, E. C. de; MELO, A. de S.; MULLER, M. et, al. O significado de cuidar para enfermeiros oncológicos. In: Simpósio Brasileiro de Comunicação em Enfermagem, 8., 2002, São Paulo. Anais eletrônicos. Escola de Enfermagem de Ribeirão Preto - USP. Disponível em:

<http://www.proceedings.scielo.br/scielo.php?pid=MSC0000000052002000200016\&script =sci_arttext $>$. Acesso em 18 set. 2009.

CHIZZOTI, A. Etnografia. In.: CHIZZOTI, A. Pesquisa qualitativa em ciências humanas e sociais. Petrópolis, RJ: Vozes, 2006.

COSTA, C. A.; LUNARDI FILHO, W.D; SOARES, N.V. Assistência humanizada ao cliente oncológico: reflexões junto à equipe. Revista Brasileira de Enfermagem, 2003; 56 (3): 310-314. 
EFKEN, K. H. A problemática da experiência ética na sociedade contemporânea. Ágora Filosófica, Pernambuco, ano. 5, n.2, p.105-124, jul./dez.2005.

FERREIRA, N.M.L.A. A difícil convivência com o câncer: um estudo das emoções na enfermagem oncológica. Revista Escola Enfermagem. USP, 1996, agosto, 30, (2): 229253.

GIL, A. C. Métodos e Técnicas de Pesquisa Social. 5. ed. São Paulo: Atlas, 1999.

GIL, A. C. Como elaborar projetos de pesquisas. São Paulo, Atlas, ed.4, 2002.

KROEFF, M. Resenha da luta contra o câncer no Brasil. Documentário do serviço Nacional de Câncer Brasília. DF, 2007.

POPIM, R. C.; BOEMER, M. R. Cuidar em Oncologia na Perspectiva de Alfred Shütz. Revista Latino Americana de Enfermagem. Set/Out 2005.

Disponível em: 〈http://www.scielo.br/pdf/rlae/v13n5/v13n5a11.pdf>. Acesso em: 21 set. 2009.

SANTOS, B. M. P. Normas e diretrizes para implementação da Sistematização de Enfermagem - SAE nas instituições de saúde Brasileiras. Rio de Janeiro, COFEN, 2007.

RECCO, D. C.; LUIZ, Cintia B.; PINTO, Maria H. O cuidado prestado ao paciente portador de doença ontológica: na visão de um grupo de enfermeiras de um hospital de grande porte do interior do estado de São Paulo. Arquivo Ciência e Saúde, São Paulo, v.2, n.2, p.85-90, abr.- jun., 2005.

SCHÜNEMANN, F. O Significado de Cuidar para Enfermeiros Oncológicos. Disponível em: <http://www.portaleducacao.com.br/arquivos/arquivos_sala/media/objeto_de_aprendizage m_significado_cuidar.pdf $>$. Acesso em 21 set. 2009.

SILVA, L. W. S. da S. et, al. Arte na enfermagem: iniciando um dialogo reflexivo. Texto e contexto - enfermagem. Florianópolis, v.14, n.1, p.120-123, jan./mar. 2005.

SILVA, J. L. L. da. O processo saúde-doença e sua importância para a promoção da saúde. Revista: Informe-se em promoção da saúde, v. 2, n. 1, p. 03-05. 2006.

SILVA, L. M. G. Aspectos éticos e cuidados paliativos. Enfermagem oncológica educação continuada. Maio/agosto, 1998.

Disponível em: <http://www.rsbcancer.com.br/rsbc/10suplemento.asp>. Acesso em 22 set.2009.

SILVA, L. M. H; ZAGO, M.M.F. O cuidado do paciente oncológico com dor crônica na ótica do enfermeiro. Revista Latinoam Enfermagem, 2001, 9 (4): 44-49. 
SOUZA, M. de L. et, al. O cuidado em Enfermagem - uma aproximação teórica. Texto e contexto - Enfermagem. Florianópolis, v. 14, n.2, p. 1-6, jun. 2005.

VISENTIM, A.; LABRONICI, L.; LENARDT, M. H. Autonomia do paciente idoso com câncer: o direito de saber o diagnóstico. Acta Paulista de Enfermagem. v. 20, n. 4. São Paulo, Out/Dez 2007. Disponível em:

<http://www.scielo.br/scielo.php?pid=S0103-

$21002007000400021 \&$ script $=$ sciarttext $\&$ tlng=e $>$. Acesso em18 set. 2009.

WALDOW, Vera Regina. Bases e Princípios do Conhecimento e da Arte da Enfermagem. Editora Vozes, 2008.

WALDOW, Vera Regina. Estratégias de ensino na Enfermagem: Enfoque no Cuidado. Editora Vozes, 2005.

ZOBOLI, E. L. C. P. A redescoberta da ética do cuidado: o foco e a ênfase nas relações. Revista Escola Enfermagem, São Paulo, p. 21-27, v. 38, n.1, 2004. 